\title{
Importance of grammar in communication
}

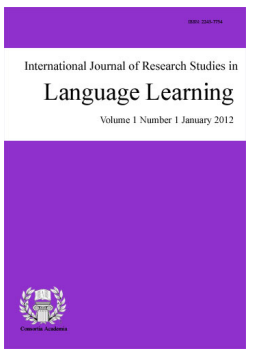

ISSN: $2243-7754$ Online ISSN: 2243-7762

Accepted: 11 May 2014
Revised: 4 May 2014 DOI: $10.5861 /$ ijrsll.2014.789

\section{Abstract}

This paper focuses on the role of Grammar in Communicative Competence and Communicative Language Teaching (CLT). Communication skills are best facilitated through CLT and it is an approach to language teaching, how learners learn from a language and the kind of classroom activities that best facilitate learning and the roles of teachers and learners in a classroom. The goal of CLT is communicative competence by not only applying grammatical rules of a language to form correct sentences, but also to know how, when and where to use these sentences and especially to whom. Grammar is the foundation for communication, which helps in the understanding the meaning and intent of a message. Recent national and international events make it clear that our country lacks quality of communication which has an impact in understanding our fellow citizens.

Keywords: grammar; Communicative Language Teaching (CLT); classroom activities; communicative competence 


\section{Importance of grammar in communication}

\section{Introduction}

Communicative Language Teaching (CLT) can be understood as a set of principles about the goals of language teaching, how learners learn a language, the kinds of classroom activities that best facilitate learning, and the roles of teachers and learners in the classroom. Since three decades communicative approach to language teaching first appeared in print in the field of second language acquisition. In various types of language institutions in Japan, including universities and colleges, language teachers and curriculum researchers having implemented communication-oriented teaching syllabi to seek for more effective ways for improving students' communication skills to replace the traditional, grammar-oriented approach of the past. With this as the theme there are two elements to be concentrated on, one is grammar and the other one is communication. Linguists define grammar as the set of structural rules that governs the composition of clauses, phrases and words in any given natural language. The term also refers to the study of such rules and this field includes morphology, syntax, and phonology, often complemented by phonetics, semantics and pragmatics (Katamba, 1996). Generally the term grammar, grammatica, referred to the art of writing, as compared to rhetoric, rhetorical, the art of speaking (Harper 2010). But the importance and the role given to grammar during the past ages can be classified. The following section focuses on the role of grammar and its importance played at different phases of Communicative Language Teaching which originated during the late 1960, and its importance at the present.

According to Jack C. Richards the trends of language teaching can be grouped into three phases. They are:

$>\quad$ Traditional approaches (up to the late 1960)

$>\quad$ Classic communicative language teaching (1970s to 1990s)

$>$ Current communicative language teaching (late 1990s to the present)

The role of grammar in each phase is discussed in the following paragraphs.

\subsection{Role of Grammar in Traditional Approaches (up to the late 1960)}

This first phase of language teaching gave priority to grammar as the basis of language proficiency. They were based on the belief that grammar could be learned through direct instruction and through a methodology that made use of repetitive practicing and drilling. The teaching of grammar was a deductive one: Students were presented with grammar rules and then given opportunities to practice them. Great attention to accurate mastery of grammar was stressed from the beginning stages of language learning. Methodologies known like the Aural oral method was implemented.

For example: Students first hear a model dialog, containing key structures that are the focus of the lesson. They repeat each line of the dialog, individually and in chorus. The teacher pays attention to pronunciation, intonation, and fluency and then corrects them. Some grammatical explanation may be offered at this point, but this is kept to an absolute minimum. Follow-up activities may take place in class where further dialog and drill work carried out (Richards \& Rodgers, 2001, pp. 64-65).

\subsection{Role of grammar in Classic Communicative Language Teaching (1970s to 1990s)}

During this season the centrality of grammar in language teaching and learning was questioned, since there was an argument that language ability involved much more than the role of grammar. While the role of grammar was needed to produce grammatically correct sentences, attention shifted to the knowledge and skills needed to use grammar and other aspects of language appropriately for different communicative purposes such as asking 
something or giving advices, describing wishes and needs and so on. What were needed to use language communicatively were communicative skills. Traditional grammar and vocabulary syllabi and teaching methods did not include information of this kind. It was assumed that knowledge of this kind would be picked up informally. The goal CLT during this time was developed within the discipline of linguistics and appealed to many within the language teaching profession, who argued that communicative skills and not simply grammatical skills should be the goal of language teaching. Activities like Mechanical, Meaningful and Communicative practices were given. Examples for mechanical practice would be repetitions drills and substitution drills designed to practice use of particular grammatical or other items. Example for meaningful practice is to practice the use of prepositions to describe locations of places. Example of communicative practice is to make students draw a map and explain it by themselves.

\subsection{The Role of Grammar in the Contemporary. (1990s to the present):}

From the year 1990 onwards the communicative approach has been implemented all over, since it describes a set of very general principles grounded in the notion of communicative approach as the goal of second and foreign language teaching, and a communicative syllabus and methodology as the way of achieving this goal, CLT has continued to evolve as our understanding of the process of second language learning has developed. The student's communicative skill is developed by linking grammatical development to the ability to communicate. And so, Grammar is not taught in isolation but often arises out of a communicative task, thus creating a need for specific items of grammar. Opportunities are provided for both inductive and deductive learning of grammar. Students at school were insisted to talk only in English to improve their communicative skills. Competitions like elocution; poem reciting, debating etc. were conducted to improve the communicative skills of a person. Grammar was taught in class along with the lessons as it was part of the syllabus and also to make the students score during examinations but, activities conducted in classes were communication oriented. But the standard of grammar teaching has improved a lot by introducing exercises which help in communicative skills. For illustration: Tasks based on grammatical skills were fill in the blanks with appropriate adjectives, nouns, etc. error spotting, identifying nouns adverbs, prose and poetry comprehensions and so on. But, introducing TG grammar and basic sentence patterns and types of sentences to develop ones communicative skills are introduced in the syllabus and are given importance too.

\section{Accuracy versus Fluency}

From these three approaches substantiating the role of grammar in each phase it is emphasized that grammar and language are related. At present the focus of every language learner and speaker is based on fluency and not accuracy.

Here are a few examples where language speakers lack accuracy.

$>$ Achieved an award...

$>\quad$...very rememberable days

$>\quad$ Make note my number...

$>\quad$ Cannot able to...

$>$ Teachers are went for...

$>\quad$ When we can go?

$>\quad \mathrm{He}$ is there..?

There are some of the grammatical errors which the learners commit while they communicate and they are unable to spot them because they lack proper grammatical knowledge. They translate what they are about to say 
directly from their mother tongue and the problem is they don't think in English; they think in their mother tongue and use a sentence pattern which contradicts English grammar. Students are void of grammar, when to use a verb or an auxiliary verb, prepositions at its place etc.

\section{Relationship between grammar and language}

The relationship between grammar to language is not simply a regulatory device but even something more than that. When grammar is prioritized over communication in the context of language, the term grammar is not used in the sense of a textbook, or in the sense of anything as specific as a set of rules of a language, such as gender, number, person, subject-verb or object-verb agreement, word order, subordinating devices and so on. In generative grammar the set of such highly abstract principles is called Universal grammar. The nature of this grammar which is the reality of language is not given but is to be hypostatized. Its reality is the fact that speakers have an internal knowledge about it although they are unable to externalize that knowledge. In this sense, then, language as it is known exists only as an epiphenomenon, as used by Chomsky. From such a perspective, it is easy to see how grammar is the real thing and language an appearance.

Thus, what is called as grammar in this abstract sense is to be seen as a set of boundary conditions under which language becomes possible. Within the boundaries however various further possibilities exist, giving rise to a whole range of multiplicities and variations. Internal choices are also responsible for language change in course of time. Languages change because of many factors, sometimes accidentally but often due to contact situations. This is not denied when it is said that 'grammar' is a priori; for whatever roles these forces play, they do not change the basic shape of language. Grammar is also the pursuit of an activity as much the way Collingwood says what art is.

In trying to arrive at an understanding of any activity, one must begin with a mass of experience related to that activity; and this experience cannot be acquired by philosophical thinking, or by scientific experiments, or by observation of the activity in other people, but only by a long and specialized pursuit of activity itself. Only after this experience has been acquired is it possible to reflect upon it and to bring to light the principles underlying it (Collingwood, 1925, pp. 8-9).

From this it is clear, that one cannot reflect on grammar without actually doing grammar. These remarks of Collingwood, made in respect of the philosophy of art, underscore the importance of doing something well before venturing to talk about it, and that applies to the field of grammar without doubt. It is liked to be said by us that doing grammar and thinking about it are simultaneous and mutually supportive activities. In the end of history, does each speaker decide his or her own grammar? Many people believe that that is how it is going to be. If so then grammar gradually loses its authenticity and we will have only a naïve theory of language. But grammar has been continuously resisting that end, and in that resistance, history too may have some hopes of survival!

\section{Different perspectives on competence}

According to Chomsky,

Linguistic theory is concerned primarily with an ideal speaker-listener, in a completely homogeneous speech community, who knows language perfectly and is unaffected by such grammatically irrelevant conditions as memory limitations, distractions, shifts of attention and interest, errors (random or characteristic) in applying his knowledge of the language in actual performance (Chomsky, 1965, p. 3).

Chomsky clearly distinguished the description of language form (competence) and language use (performance) and established that the speaker-listener's internal grammar that judges the grammaticality of sentences should be the main object of investigation for linguists. 
According to Dell Hymes communicative competence is "appropriateness of sociocultural significance of utterance" (Canale \& Swain, 1980). Hymes (1974), retaining the idea of Chomsky's underlying grammatical competence, looks at contextual relevance as one of the crucial aspects of one's knowledge of language and claims that meaning in communication is determined by its speech community and actual communicative event in question, which consists of the following components he calls SPEAKING (a mnemonic code word): Setting, Participants, Ends, Act sequence, Key, Instrumentalities, Norms of interaction and interpretation and Genre (Hymes, 1974). These are broadly considered speech contexts in which real verbal interactions takes place.

\section{Conclusion}

From what has been read before it is realized that without rules there is chaos. Grammar is merely a set of rules to preserve the written word. Without these standards there would be no continuity of language and over time communication of ideas would suffer. As people from different parts of the world try to talk in English which is influenced by their own mother tongue, there are errors in grammar and sentence pattern. If one can master grammar, He or She can unlock ideas and thoughts that were written across time and place. Proper grammar is very important. Correct grammar keeps from being misunderstood and lets us effectively express our thoughts and ideas. The way we communicate is extremely important in our profession and society. While modern technology and social media have less formal forms of communication, we are expected to produce perfect grammar in professional settings. Glaring errors in spellings and punctuation are judged before the content of the work. Grammar gives language users the control of expression and communication in everyday life. Mastery over the words help speakers communicate their emotions and purpose more effectively. Even though changes in grammar are made from old to contemporary, grammar can change its shape according to the trend but the importance or the role played by grammar still remains the same.

\section{References:}

Harper, D. (8 April 2010). Online etimological dictionary.

Huddleston, R., \& Pullum, G. K. (2002). The Cambridge grammar of English language. Cambridge: University of Cambridge.

Littlewood, W. (1981). Communicative language teaching. Cambridge: University of Cambridge.

O' Grady, W., Dobrovolsky, M., \& Katamba, F. (1996). Contemporary linguistics: An introduction. Essex: Longman.

R.G, C. (2012). History as a science. New York: Oxford University Press.

Richards, J. C. (2006). Communicative language teaching today. Cambridge: University of Cambridge.

Tirumalesh, K. (1999). Grammar and communication. New Delhi: Allied Publishers. 
Praise, S. \& Meenakshi, K. 